\title{
The Influence of Solar-Induced Thermal Effect on Outdoor Ventilation within Generic Urban Neighbourhood
}

\author{
Guoxing Chen, Li Rong, Guoqiang Zhang \\ Department of Engineering, Aarhus University, Aarhus, Denmark
}

\begin{abstract}
As the ever-fasting urbanization, it is important to understand urban flow for the health of urban dweller. The previous studies on urban flow are conducted under the isothermal condition, and seldom pay attention to the solar-induced thermal effect. In this paper, one-way coupling CitySim-CFD is conducted to evaluate influence of solar-induced heating on urban flow within generic urban neighbourhood based on the climate characteristic and building codes of China. The results show that the differences in urban flow between isothermal condition and solar-induced heating condition become significant as the increase of Richardson number. The solar-induced heating have strong influence on outdoor wind environment, while the impact on outdoor ventilation is not significant. Meanwhile, the hourly distributions of Richardson number in each investigated city are presented in this paper, which can be a guideline for whether the results from isothermal cases are feasible. More investigations should be conducted to characterize the effect of solar-induced heating on urban ventilation parametrically.
\end{abstract}

\section{Introduction}

With the rapid urbanization, the portion of the population living in urban areas has continuously increased. In 2018, $55 \%$ of the world's population was lived in urban area, while it is estimated to reach $68 \%$ by 2050 (The Population Division, 2018). As the building density becomes higher, the air quality has been deteriorating within the urban canopy layer, also the urban heat island effect (UHI). Good outdoor ventilation is one of the possible solution to help diluting pollutant and heat.

Current studies of flow in urban mainly conducted with generic building configurations and real complex building configurations in the spatial scale of regional $(<200 \mathrm{~km})$, city $(<20 \mathrm{~km})$, neighbourhood $(<2 \mathrm{~km})$ and street $(<0.2$ $\mathrm{km})$ (Britter and Hanna, 2003). Most of the studies on pedestrian comfort were conducted at the scale from street to neighbourhood with field measurement, wind-tunnel experiment and computational fluid dynamics (CFD) simulation (Blocken, Janssen and van Hooff, 2012; Shahrestani et al., 2015; Antoniou et al., 2017). As the flow patterns are determined by the building configurations, studies with real building configurations are performed as case study of local wind environment (Panagiotou et al., 2013; Toparlar et al., 2015), or investigate the possibilities and limitations of CFD for real urban areas (Antoniou et al., 2017). Studies with generic buildings configuration not only provide windtunnel experimental data for CFD validation (Brown et al., 2000; Uehara et al., 2000; Allegrini, Dorer and Carmeliet, 2013), but also provide the basic insights of the relationship between urban morphology and urban ventilation (Abd Razak et al., 2013; Ignatius, Wong and Jusuf, 2015; Ramponi et al., 2015; Taleghani et al., 2015). Large parts of urban flow have investigated the influence of urban length, building height variations, building layouts, wind directions etc. (Hang et al., 2010, 2015; Yuan and Ng, 2012; Buccolieri et al., 2015) the under neutral atmospheric condition. Thermal effect is another key issue determining urban microclimate. Field measurement in Nantes (Louka et al., 2002) during summer time shown that the maximum building walls' temperature in the afternoon exceed $50{ }^{\circ} \mathrm{C}$, which cause strong buoyancy effect on the flow around the buildings. Wind-tunnel experiment with uniform wall heating (Allegrini, Dorer and Carmeliet, 2014) indicates that the air change rate $(A C H)$ inside the street canyon increases strongly with increasing walls' temperature. As building walls are heated up by solar radiation which depends on solar position and site location, the building walls' temperature are not uniform in real scenario. The orientation of thermal stratification will affect the flow structure (Jae-Jin and Jong-Jin, 1999).

One of the most employed simulation tool is ENVI-met, which is simplified 3D model designed to simulate the interaction between surfaces, plants and air in an urban environment (Bruse and Fleer, 1998). While its resolution is rather too low (minimum $0.5 \mathrm{~m}$ ), and has shortcoming in capturing the long-wave and short-wave radiations (O'Malley et al., 2015). Coupling CFD and solar radiation model can capture the solar radiation and obtain higher spatial resolution of local wind-thermal environment. Saneinejad, etc., (2014) conducted CFD simulation with radiation and porous media model to study the local UHI within a two-dimension street canyon. Santiago, ect., (2014) coupled CFD simulation with TUF3D model to investigate the influence of solar radiation within a threedimension street canyon. The results show that the flow regime is completely changed with respect to neutral case. Nazarian and Kleissl (2016) simulated the urban environment with solar-induce surface heating by using ANSYS Solar Load Model, it shows that the ACH inside the street canyon is a function of horizontal temperature 
gradient. The urban energy model, CitySim, has detailed radiation models for solar radiation and radiation exchange between neighbouring buildings, the ground and environment with scale ranging from a small neighbourhood to an entire city. It is capable of computing the hourly irradiation on building surfaces and the corresponding surfaces' temperature. Researchers have coupled CitySim and CFD to reveal the influence of neighbourhood morphologies, building height topology and surface albedo on local heat island (Allegrini, Dorer and Carmeliet, 2015; Allegrini and Carmeliet, 2017, 2018).

As the ever-fasting urbanization of China, the building density will be higher on the foreseeing days, it is important to improve urban ventilation for the health of people and energy saving. Meanwhile China covers a wide temperature gradient decreasing from south to north and a large precipitation gradient decreasing from southeast to northwest (WU, 2005), it can be an ideal place to study the wind-thermal environment within urban neighbourhood. In this paper, One-way coupling CitySim-CFD is applied to investigate the influence of solar-induced heating on the outdoor ventilation within typical generic urban neighbourhoods.

\section{Methods and materials}

$\lambda_{f}$ (frontal area ratio, ratio of building frontal area to ground surface area) and $\lambda_{p}$ (plan area ratio, ratio of building roof to ground surface area) are the typical parameters to describe the urban morphology (Grimmond and Oke, 1999). For typical urban morphology, $\lambda_{f}=$ $\lambda_{p}=0.25$ (medium size). The typical urban neighbourhood-scale models in the field of urban ventilation are square layout and staggered layout.

In this paper, we take the medium size square layout as the investigated target. The building width $(B)$, building height $(H)$ and distance between buildings $(W)$ are the same $(B=H=W=30 \mathrm{~m})$, as Figure 1 shows.

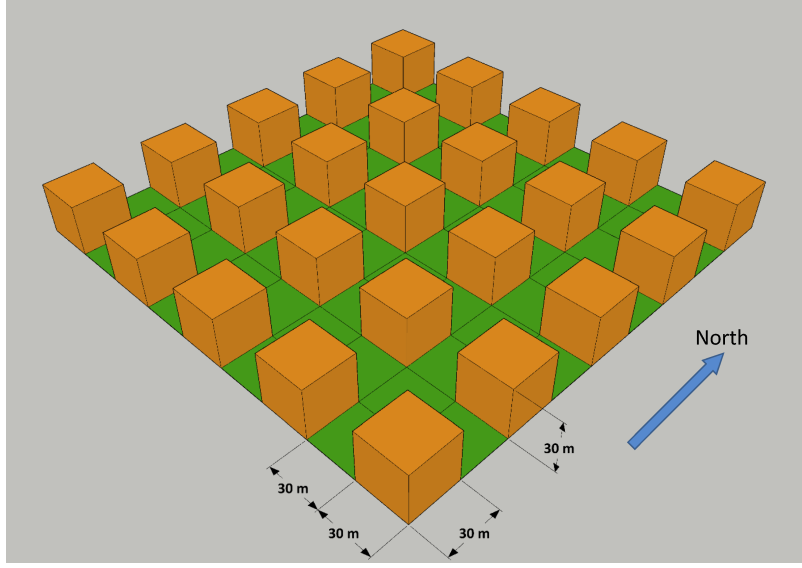

Figure 1: The studied neighbourhood-scale model.

With the fixed array's parameters, CitySim and CFD are coupled to study the outdoor ventilation within the generic neighbourhood-scale building array under the five different climate zones of China. The numerical simulation methodology is that the CitySim generates the solar-induced temperatures of building walls and ground surfaces as thermal boundary conditions for CFD simulation.

\section{CitySim setup}

The climate data (typical year) and horizon characteristics of the investigated locations for CitySim simulation are derived from Meteonorm.

The key building thermal parameters and glazing ratio of each investigated city are summarized in Table 1, which are complied with Chinese Design Standards for energy efficiency of public buildings and the standards of each investigated city (MOHURD, 2016; Tong et al., 2016). The infiltration is set as $1 h^{-1}$, with space heating and cooling to maintain the indoor air temperature between 18 and $26^{\circ} \mathrm{C}$. The openable faction of windows is $50 \%$ with the shading device of $50 \%$, and the solar reflectance of all surfaces is 0.5 . The ground surfaces inside the building array is set as asphalt with a reflectance of 0.5 .

Table 1: Building thermal parameters and glazing ratio of investigated cities.

\begin{tabular}{|c|c|c|c|c|c|c|}
\hline & & Guangzhou & Kunming & Shanghai & Beijing & Harbin \\
\hline \multirow{3}{*}{$\begin{array}{c}\text { Surfaces' U-value } \\
{\left[\mathrm{W} /\left(\mathrm{m}^{2} \cdot \mathrm{K}\right)\right]}\end{array}$} & Wall & 0.72 & 0.72 & 0.54 & 0.46 & 0.35 \\
\cline { 2 - 7 } & Roof & 0.44 & 0.44 & 0.39 & 0.39 & 0.25 \\
\cline { 2 - 7 } & Floor & 1.32 & 1.32 & 0.46 & 0.46 & 0.25 \\
\hline \multirow{2}{*}{$\begin{array}{c}\text { Windows' U-value } \\
{\left[\mathrm{W} /\left(\mathrm{m}^{2} \cdot \mathrm{K}\right)\right]}\end{array}$} & U-value & 2.40 & 2.40 & 2.30 & 1.77 & 1.76 \\
\cline { 2 - 7 } & G-value & 0.20 & 0.20 & 0.32 & 0.37 & 0.68 \\
\cline { 2 - 7 } Glazing ratio & North & 0.45 & 0.40 & 0.35 & 0.30 & 0.25 \\
\cline { 2 - 7 } & East & 0.30 & 0.35 & 0.25 & 0.35 & 0.30 \\
\cline { 2 - 7 } & South & 0.50 & 0.45 & 0.50 & 0.50 & 0.45 \\
\cline { 2 - 7 } & West & 0.30 & 0.35 & 0.25 & 0.35 & 0.30 \\
\cline { 2 - 7 } & Roof & 0.04 & 0.04 & 0.04 & 0.04 & 0.04 \\
\hline
\end{tabular}

\section{CFD setup}

All simulation cases are conducted as steady state with standard $k-\varepsilon$ model that solves turbulence equations and the energy conservation equation with temperature as the solved variable. In addition, buoyancy terms are accounted for with Boussinesq's approximation. The simulation cases are solved by the commercial code
STARCCM+. The computational domain extends $6.7 H$ upstream and $50 H$ downstream of the building array, height of the domain is $5 H$.

The inlet vertical profile of stream-wise velocity $U(z)$, the turbulent kinetic energy $k(z)$ and the turbulence dissipation $\varepsilon(z)$ was described by equation (1) to (3). This neutral atmospheric boundary layers (Richards and 
Hoxey, 1993) are commonly used in CFD simulations of urban flow.

$$
\begin{gathered}
U(z)=\frac{u_{A B L}^{*}}{k} \ln \left(\frac{z+z_{0}}{z_{0}}\right) \\
k(z)=\frac{u_{A B L}^{*}{ }^{2}}{\sqrt{C_{\mu}}} \\
\varepsilon(z)=\frac{u_{A B L}^{*}{ }^{3}}{k_{v}\left(z+z_{0}\right)} \\
k_{S}=9.793 z_{0} / C_{S}
\end{gathered}
$$

Where, $u_{A B L}^{*}$ is the atmospheric boundary layer friction velocity, $m / s . k$ is von Karman constant (0.42). $C_{\mu}=0.09$ denotes the model constant. Roughness $z_{0}=0.1 \mathrm{~m}$ and roughness constant $C_{s}=4$, then the roughness height of the ground, $k_{\mathrm{s}}=0.245 \mathrm{~m}$. The distance between the centre point $P$ of the ground adjacent cell and the ground surface $\left(z_{\mathrm{P}}\right)$ should be larger than $k_{s}, z_{p}=0.25 \mathrm{~m}$ is adopted. The reference velocities $\left(U_{r e f}\right)$ at the reference height $10 \mathrm{~m}$ are based on the investigated cities' weather data.

At the lateral sides and roof of the computational domain, the symmetry boundary condition is applied. The building walls are simulated as smooth, and the floors are simulated as rough with the roughness height of $z_{p}=0.25 \mathrm{~m}$.

The thermal boundary conditions of building walls and ground surfaces within the building array are set as the temperatures simulated by CitySim. The ground surfaces within the building array are divided into patches of $10 \mathrm{~m}$ x $10 \mathrm{~m}$. While the thermal boundary condition of the ground outside the array is set as ambient temperature in order to avoid heating up of the air in the approach flow (Allegrini and Carmeliet, 2017). Even though the twoway coupling, where the walls' temperatures would also change as the local wind velocities, would gain more precise results of wind-thermal environment. While the aim of this study is to investigate the influence of solarinduced thermal effect, the lower precise results obtained by one-way coupling can be accepted.

In mesh generation, polyhedral mesh and prism layer mesh are employed, the first prism layer is set as $0.5 \mathrm{~m}$. The cells number of each the case is around 7 million, and the wall $y+$ ranges from 70 to 3000 of the wall surfaces within the building array. The isothermal case is validated with wind tunnel experimental data (Brown et al., 2000), grid sensitivity study is also conducted.

The hottest hours are chosen as the investigated summer scenarios. In addition, the winter scenarios are set at 17:00 $\mathrm{PM}$ at $15^{\text {th }}$ January when the ambient air temperatures are closer to the coldest temperatures. The weather data of the investigated scenarios are summarized in Table 2 and Table 3. The wind speed is measured at height of $10 \mathrm{~m}$. For wind direction, $360^{\circ}$ represent the north.

Table 2: Weather data of the summer scenarios in the investigated cities.

\begin{tabular}{|c|c|c|c|c|c|c|c|}
\hline City & Month & Day of the month & Hour & $\begin{array}{c}\text { Ambient air } \\
\text { temperature }\left({ }^{\circ} \mathbf{C}\right)\end{array}$ & $\begin{array}{c}\text { Wind speed } \\
(\boldsymbol{m} / \mathbf{s})\end{array}$ & $\begin{array}{c}\text { Wind direction } \\
\left({ }^{\circ}\right)\end{array}$ & $\begin{array}{c}\text { Richardson } \\
\text { number }\end{array}$ \\
\hline Guangzhou & 7 & 31 & $16: 00$ & 38.1 & 7.4 & 291 & 0.09 \\
\hline Kunming & 7 & 9 & $16: 00$ & 29.8 & 5.7 & 294 & 0.26 \\
\hline Shanghai & 7 & 21 & $16: 00$ & 38.0 & 1.8 & 82 & 3.35 \\
\hline Beijing & 7 & 9 & $14: 00$ & 37.8 & 5.1 & 283 & 0.35 \\
\hline Harbin & 6 & 19 & $16: 00$ & 34.3 & 3.4 & 296 & 0.61 \\
\hline
\end{tabular}

Table 3: Weather data of the winter scenarios in the investigated cities.

\begin{tabular}{|c|c|c|c|c|c|c|c|}
\hline City & Month & Day of the month & Hour & $\begin{array}{c}\text { Ambient air } \\
\text { temperature }\left({ }^{\circ} \mathbf{C}\right)\end{array}$ & $\begin{array}{c}\text { Wind speed } \\
(\mathbf{m} / \mathbf{s})\end{array}$ & $\begin{array}{c}\text { Wind direction } \\
\left({ }^{\circ}\right)\end{array}$ & $\begin{array}{c}\text { Richardson } \\
\text { number }\end{array}$ \\
\hline Guangzhou & 1 & 15 & $17: 00$ & 8.9 & 3.7 & 357 & 0.17 \\
\hline Kunming & 1 & 15 & $17: 00$ & 7.4 & 4.1 & 357 & 0.20 \\
\hline Shanghai & 1 & 15 & $17: 00$ & -0.8 & 3.8 & 42 & 0.00 \\
\hline Beijing & 1 & 15 & $17: 00$ & -5.0 & 4.3 & 42 & 0.12 \\
\hline Harbin & 1 & 15 & $17: 00$ & -21.9 & 3.9 & 357 & 0.05 \\
\hline
\end{tabular}

\section{Evaluation indices}

Velocity ratio $\left(V_{r}\right)$ is a simple index to indicate the wind environment at pedestrian level of the investigated site, is calculated as:

$$
V_{r}=U_{P} / U_{r e f}
$$

Where $U_{P}$ is the wind velocity at pedestrian level $(1.75 \mathrm{~m}$ above the ground), $U_{\text {ref }}$ is the wind velocity at the top of the wind boundary layer not affected by investigated site feature (ground roughness and buildings). In this study, the $U_{\text {ref }}$ is the same as inlet boundary, at the reference height $10 \mathrm{~m}$.
Air change rate $(A C H)$, air exchange per hour for a control volume, is widely used in urban ventilation to represent the overall ventilation efficiency.

$$
A C H=3600 * Q_{T} / \text { vol }
$$

Where $Q_{T}$ is the total flow rate entering the control volume; vol is control volume, the entire neighbourhood model; 3600 represent 1 hour is 3600 seconds.

Normalized velocity ratio $\left(V_{r}^{*}\right)$, the difference between heating condition and isothermal condition, indicates the change of wind environment caused by buoyancy effect:

$$
V_{r}^{*}=V_{r, \text { heating }} / V_{r, \text { isothermal }}
$$


Normalized air change rate $\left(A C H^{*}\right)$, the difference between heating condition and isothermal condition, indicates the change of outdoor ventilation efficiency caused by buoyancy effect:

$$
A C H^{*}=A C H_{\text {heating }} / A C H_{\text {isothermal }}
$$

Richardson number $(R i)$, the ratio of buoyancy to inertia farces, is non-dimensional number reflect the importance of buoyancy.

$$
R i=g \beta H\left(T_{0}-T_{r e f}\right) / U_{r e f}^{2}
$$

Where $T_{r e f}$ is the reference temperature, $U_{r e f}$ is the reference velocity, here we take ambient air temperature and reference velocity at the inlet as reference temperature and velocity. $T_{0}$ is temperature of walls, here we take it as the average temperature of all building walls and ground surfaces inside the neighbourhood model. $g=9.81 \mathrm{~m} \cdot \mathrm{s}^{-2}$ is the gravity acceleration. $H$ is the building height. $\beta$ is the thermal expansion rate of air, here is $0.0033 K^{-1}$.
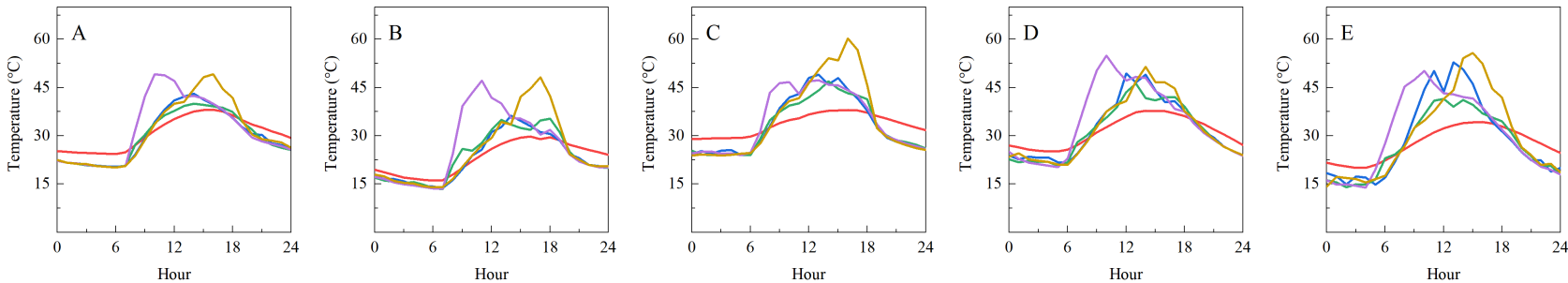

Figure 2: Temperatures of buildings' walls in the hottest hours (A: Guangzhou, B: Kunming, C: Shanghai, D: Beijing, E: Harbin; Red line: ambient air temperature, Blue line: south wall, Green line: north wall, Purple line: east wall,

Yellow line: west wall).

\section{Pedestrian wind-thermal environment}

Figure 3 to Figure 7 present the $V_{r}$ and $\Delta t$ at pedestrian level in the five investigated cities under isothermal condition and solar-induced heating condition. Generally, for the case in Guangzhou ( $R i=0.09)$, Kunming $(R i=0.26)$ and Beijing $(R i=0.35)$ the airflow patterns are similar under isothermal condition and solar-induced heating condition. But still exist small differences in the downstream. When the Richardson number is getting larger, in the case Harbin $(R i=0.61)$, the local differences in flow pattern become obvious.

\section{Results}

\section{Solar-induced thermal condition}

The temperatures of building walls within the layout are proximately the same in each orientation. Figure 2 shows the average wall temperature of each studied city in the hottest day respectively. The walls' temperature are resulted from solar radiation and buildings' thermal characteristic (especially the albedo), it will be the same under the same building distance in specified time. In the hottest hour of each investigated city, west orientation walls have the highest temperature. The highest wall temperature happens in Shanghai, exceed $60^{\circ} \mathrm{C}$. The temperatures of walls and ground surfaces in the investigated hours are set as thermal boundary conditions in CFD to simulate the outdoor wind-thermal environment.
For the case in Shanghai $(R i=3.35)$, the flow pattern is totally different with respect to isothermal case. The $V_{r}$ within the canyon is larger than 1 , which means the buoyancy force is dominating the airflow and increases wind velocity. Consequently, more heat is diluted from the canyon.

The Richardson numbers of the winter scenarios selected here are quite low (see Table 3), the general airflow pattern between the isothermal condition and solarinduced heating are similar.
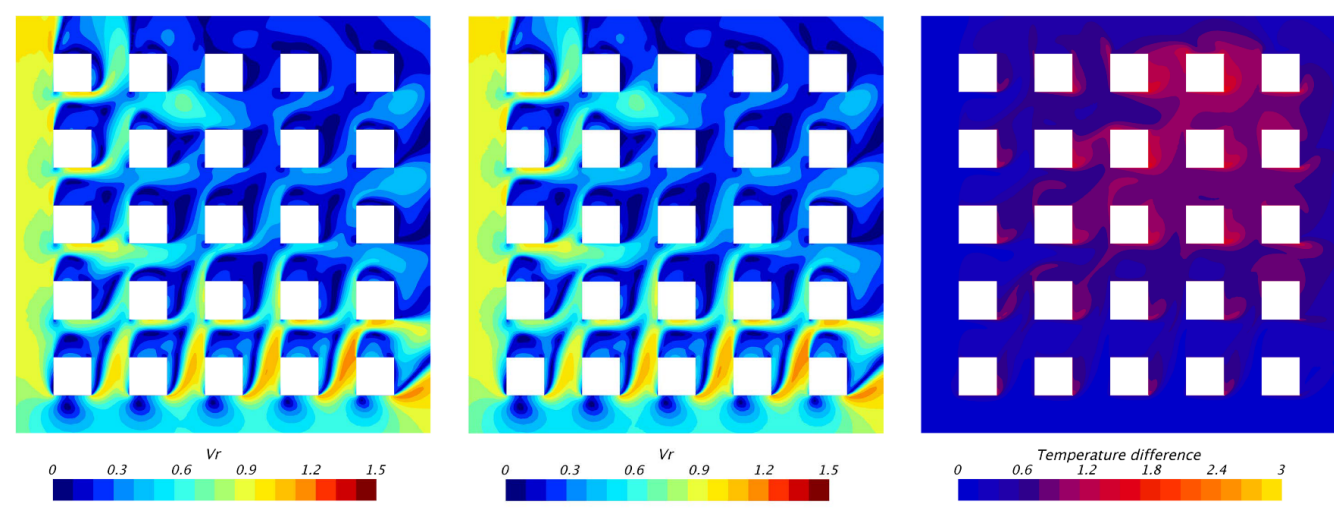

Isothermal case

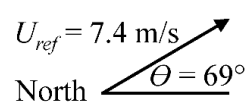

Solar-induced heating case

Figure 3: $V_{r}$ and $\Delta t$ in the hottest hour of Guangzhou $(R i=0.09)$. 

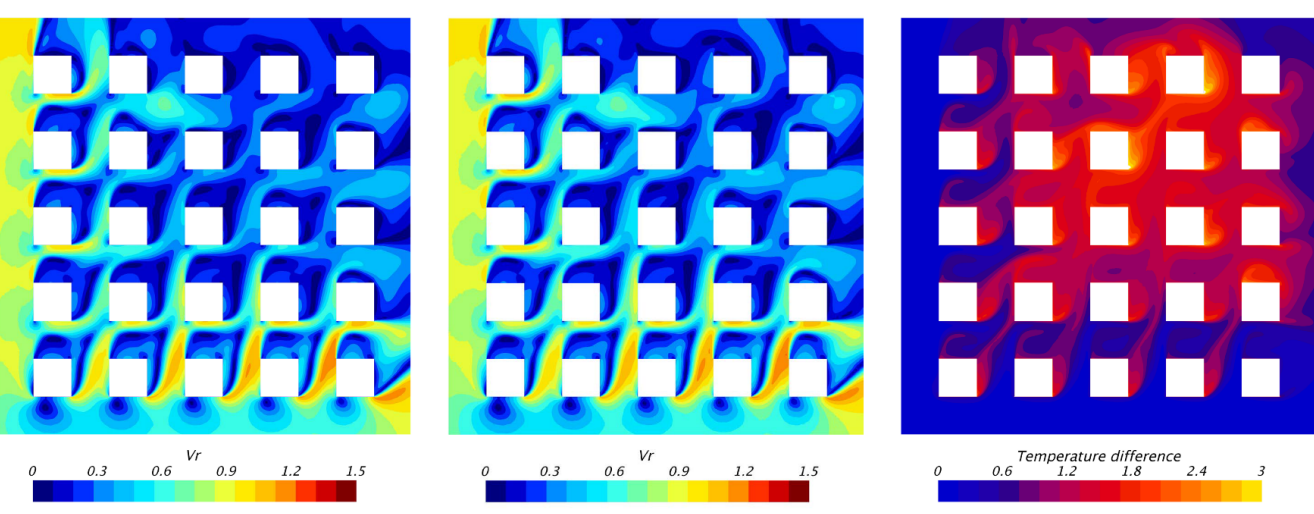

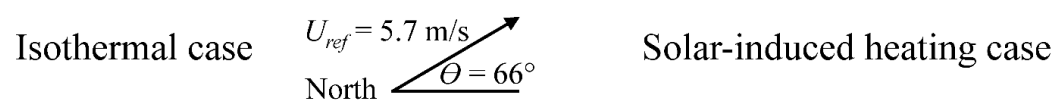

Figure 4: $V_{r}$ and $\Delta t$ in the hottest hour of Kunming $(R i=0.26)$.
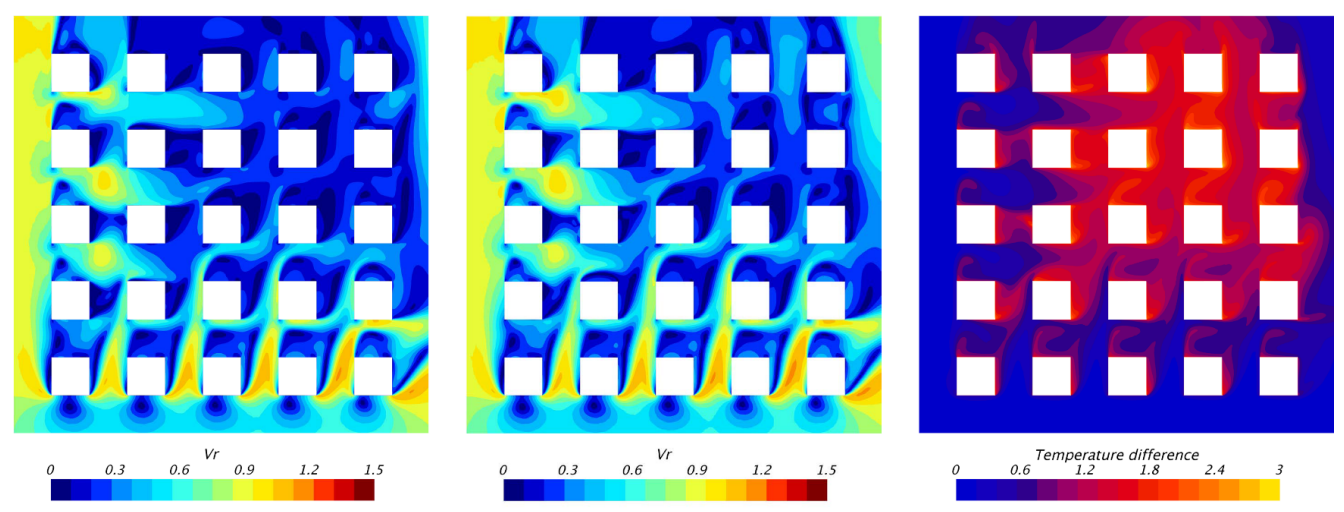

Isothermal case $\quad U_{r e f}=5.1 \mathrm{~m} / \mathrm{s}>$

North $O=77^{\circ}$

Solar-induced heating case

Figure 5: $V_{r}$ and $\Delta t$ in the hottest hour of Beijing $(R i=0.35)$.
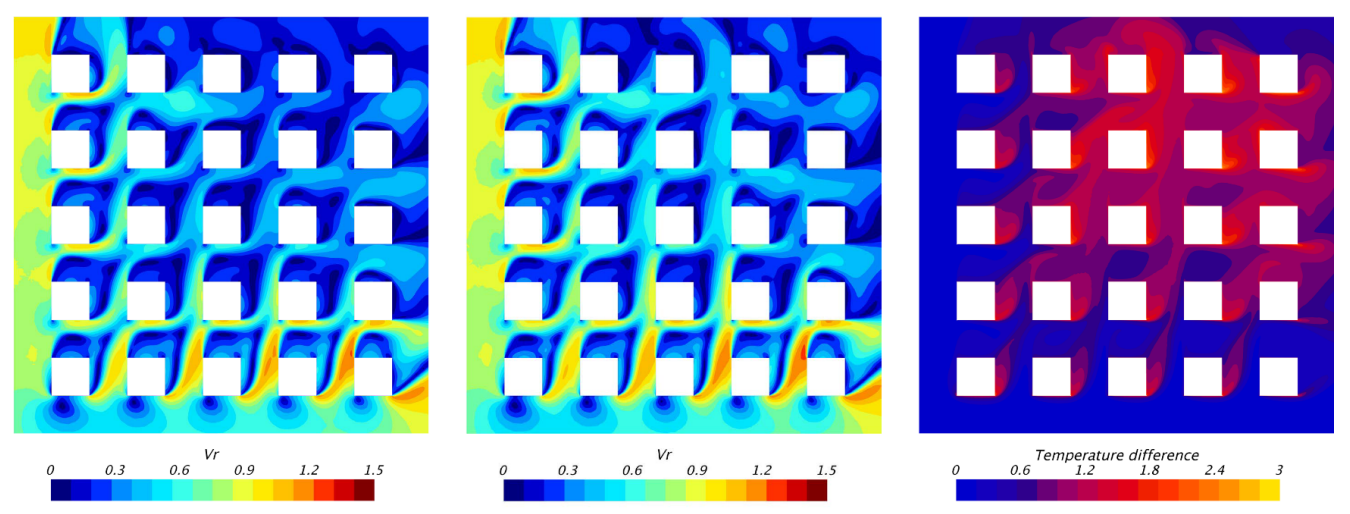

Isothermal case $U_{r e f}=3.4 \mathrm{~m} / \mathrm{s}$

Solar-induced heating case

North $\theta=64^{\circ}$

Figure 6: $V_{r}$ and $\Delta t$ in the hottest hour of Harbin $(R i=0.61)$. 

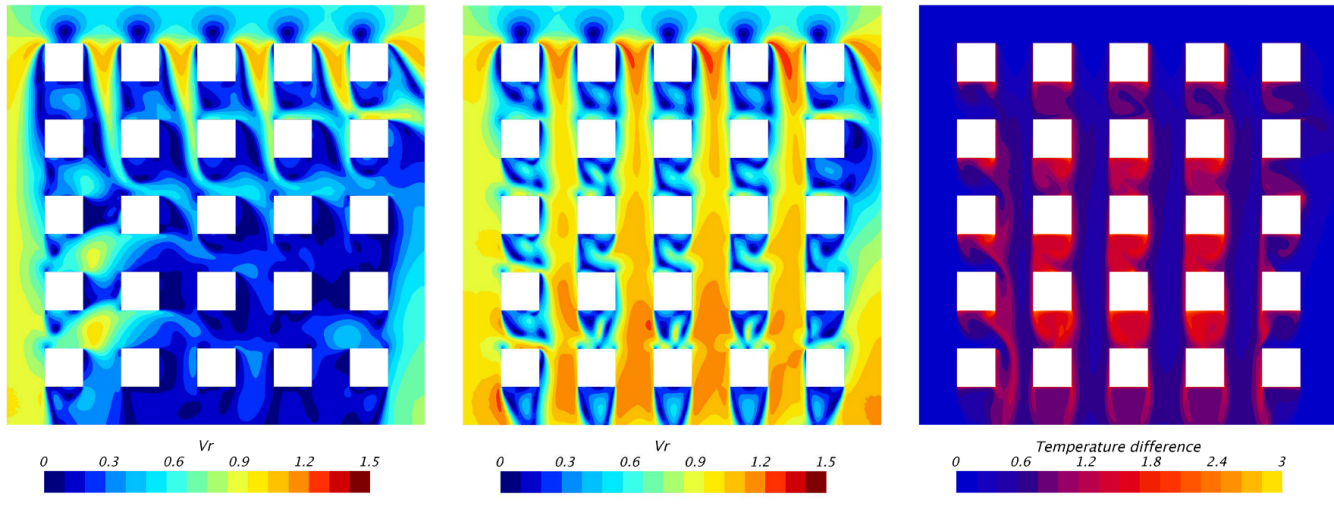

Isothermal case

Solar-induced heating case

North $\theta=82$.

(

Figure 7: $V_{r}$ and $\Delta t$ in the hottest hour of Shanghai $(R i=3.35)$.

\section{Analysis of solar-induced thermal effect}

The $R i$ of each case are calculated to quantify the solarinduced thermal effect. The variation of $V_{r}^{*}$ and $A C H^{*}$ with $R i$ are presented in Figure 8. In this paper, $R i$ ranges from 0 to 3.35. When $R i$ closes to 0 , the difference of velocity ratio between isothermal and heating condition is quite small, even can be ignored. As the $R i$ becomes larger, the buoyancy effect becomes obvious and even dominates the airflow. The influence of solar-induced

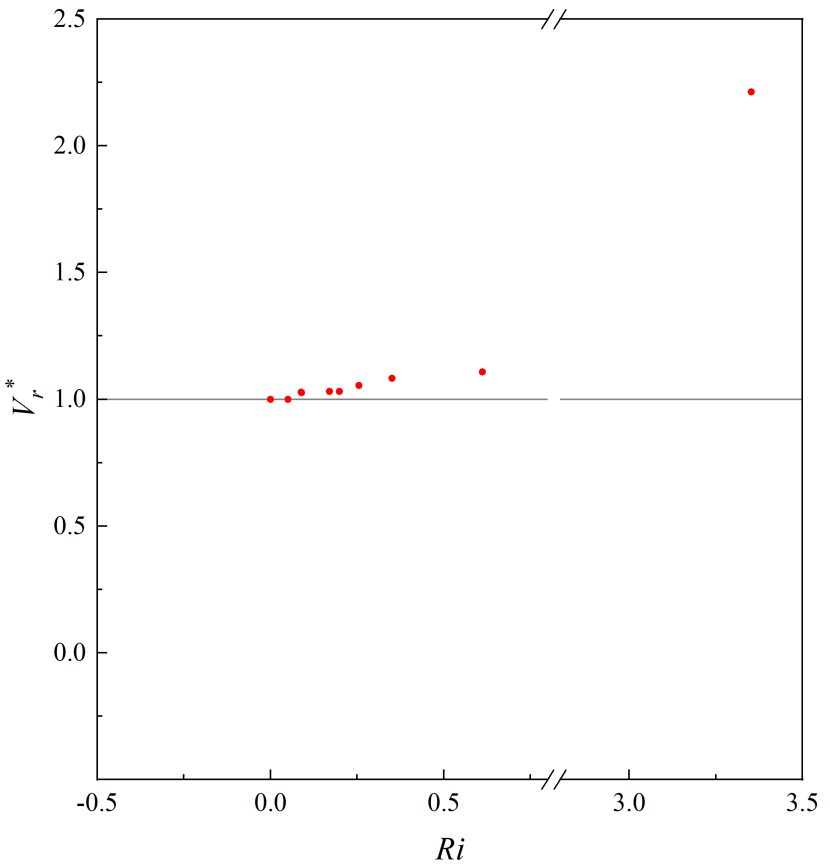

thermal effect on the air change rate are not significant. The maximum normalized air change rate is 1.14 with $R i=3.35$. For $R i<0.5$, the normalized air change rate is almost 1 , the solar-induced heating does not affect the ventilation efficiency of the neighbourhood canopy. Previous research indicates that the street canyon flow is buoyancy dominated for $R i>0.5-1.0$ (Fernando et al., 2010), which is also coincided with this study of neighbourhood canopy flow.

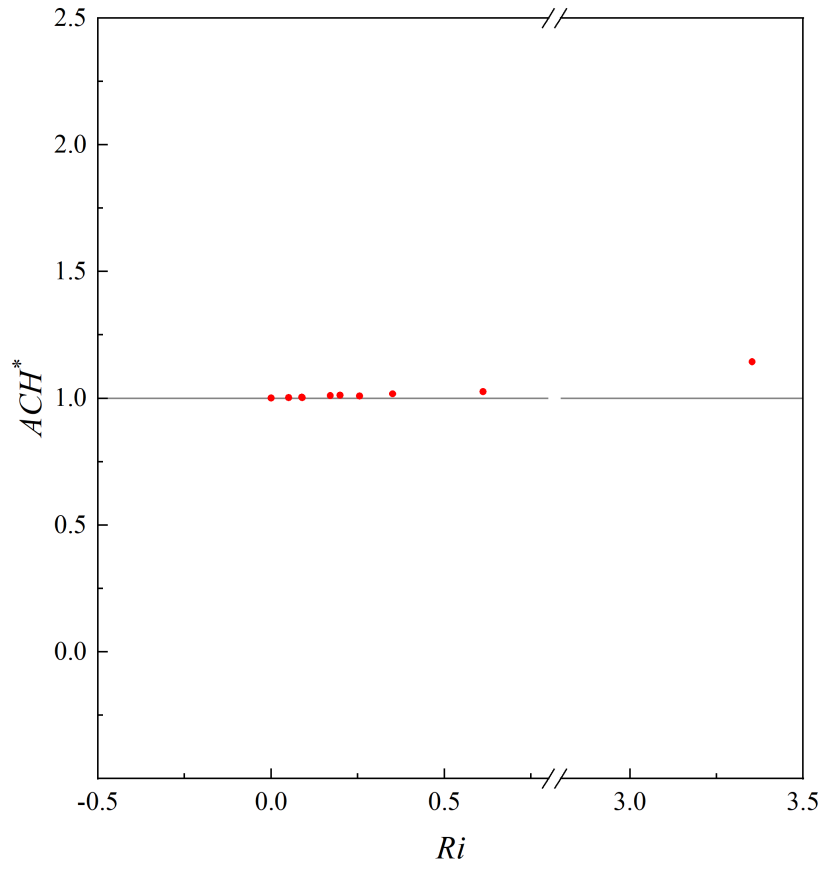

Figure 8: Variation of $V_{r}^{*}$ and $A C H^{*}$ with Richardson number.

While the investigated Richardson numbers are the extreme hottest and coldest hours in the five cities. Figure 9 shows the distribution of hourly $R i$ in each investigated city. The hourly $R i$ is divided into $R i<0,0 \leq R i<0.5$ and $R i>0.5$. The solar-induced thermal stratification of each city are not the same as their own climate conditions and building thermal characteristics. For the five cities, the Richardson number is smaller than 0 for more than half the times. When $R i<0$, the walls' temperature are lower than the ambient temperature, which likely occur in the cold hours or night-time. Further investigations should be conducted to demonstrate the solar-induced thermal effect under $R i<0$. For the five cities, the influence of solarinduced heating is small or can be ignored in less than $20 \%$ of the time. The hours of Ri>0.5 increases in the northern cities of China, where have lower ambient temperature than the southern cities. 


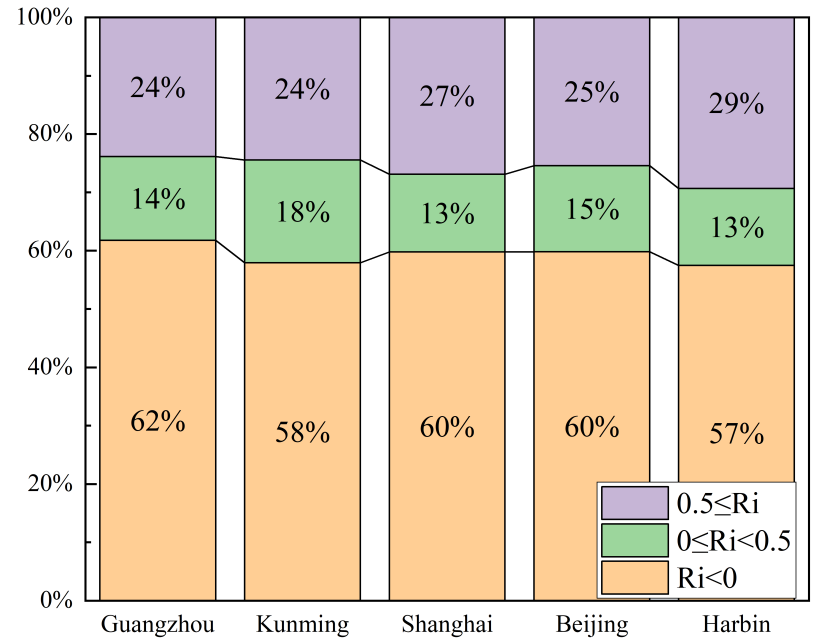

Figure 9: Distribution of hourly Richardson number in each investigated city.

\section{Discussion}

In order to obtain the corresponding $R i$, the inlet boundary conditions (ambient air temperature, reference wind velocity and wind angle) of each case are consistent with the boundary conditions of CitySim. The initial conditions of each case are not the same, later investigation should consider the influence of wind speed and direction. Meanwhile the setting of albedo is neutral (0.5), but it did reflect the complicated thermal stratification within the urban neighbourhood canopy. As Richardson number is depend on the climate characteristic and building configurations (building layout, canopy length, building height and surface albedo), further investigation should be done with wider range of $R i$ (especially $R i<0$ ) for more general conclusions. Meanwhile, this paper just investigated one urban morphology $\left(\lambda_{f}=\lambda_{p}=0.25\right)$, the influences of urban morphology and building thermal characteristics on $R i$ are another topic under consideration.

\section{Conclusion}

In this paper, one-way coupling CitySim-CFD is employed to investigate influence of solar-induced heating on outdoor ventilation within generic urban neighbourhood. Results show that the solar-induced thermal effect will affect the pedestrian level wind environment significantly, while it is not significant in analysis of urban ventilation. Unlike the previous studies under isothermal condition or uniform-heating condition, the solar-induced heating will cause non-uniform thermal stratification within the urban neighbourhood canopy, which alters the airflow pattern consequently. Whether the conclusions from isothermal cases are feasible should base on the investigated scenarios of location and time. More investigations should be conducted to characterize the effect of solar-induced heating under different urban morphologies parametrically.

\section{References}

Abd Razak, A., Hagishima, A., Ikegaya, N. and Tanimoto, J. (2013). Analysis of airflow over building arrays for assessment of urban wind environment. Building and Environment, 59, 56-65.

Allegrini, J. and Carmeliet, J. (2017). Coupled CFD and building energy simulations for studying the impacts of building height topology and buoyancy on local urban microclimates. Urban Climate, 21, 278-305.

Allegrini, J. and Carmeliet, J. (2018). Simulations of local heat islands in Zürich with coupled CFD and building energy models. Urban Climate, 24, 340-359.

Allegrini, J., Dorer, V. and Carmeliet, J. (2013). Wind tunnel measurements of buoyant flows in street canyons. Building and Environment, 59, 315-326.

Allegrini, J., Dorer, V. and Carmeliet, J. (2014). Buoyant flows in street canyons: Validation of CFD simulations with wind tunnel measurements. Building and Environment, 72, 63-74.

Allegrini, J., Dorer, V. and Carmeliet, J. (2015). Influence of morphologies on the microclimate in urban neighbourhoods. Journal of Wind Engineering and Industrial Aerodynamics, 144, 108-117.

Antoniou, N., Montazeri, H., Wigo, H., Neophytou, M.K.A., Blocken, B. and Sandberg, M. (2017). CFD and wind-tunnel analysis of outdoor ventilation in a real compact heterogeneous urban area: Evaluation using "air delay." Building and Environment, 126(October), 355-372.

Blocken, B., Janssen, W.D. and van Hooff, T. (2012). CFD simulation for pedestrian wind comfort and wind safety in urban areas: General decision framework and case study for the Eindhoven University campus. Environmental Modelling and Software, 30, 15-34.

Britter, R.E. and Hanna, S.R. (2003). Flow and Dispersion in Urban Areas. Annual Review of Fluid Mechanics, 35(1), 469-496.

Brown, M.J.M., Lawson, R.R.E., Decroix, D.S. and Lee, R.L. (2000). Mean flow and turbulence measurements around a 2-D array of buildings in a wind tunnel. 11th Joint Conference on the Applications of Air Pollution Meteorology with the Air and Waste Management Association p. Long Beach, United states.

Bruse, M. and Fleer, H. (1998). Simulating surface-plantair interactions inside urban environments with a three dimensional numerical model. Environmental Modelling and Software, 13(3-4), 373-384.

Buccolieri, R., Salizzoni, P., Soulhac, L., Garbero, V. and Di Sabatino, S. (2015). The breathability of compact cities. Urban Climate, 13, 73-93.

Fernando, H.J.S., Zajic, D., Di Sabatino, S., Dimitrova, R., Hedquist, B. and Dallman, A. (2010). Flow, turbulence, and pollutant dispersion in urban atmospheres. Physics of Fluids, 22(5), 1-20.

Grimmond, C.S.B. and Oke, T.R. (1999). Aerodynamic Properties of Urban Areas Derived from Analysis of Surface Form. Journal of Applied Meteorology, 38(9), 1262-1292. 
Hang, J., Li, Y., Sandberg, M. and Claesson, L. (2010). Wind conditions and ventilation in high-rise long street models. Building and Environment, 45(6), 1353-1365.

Hang, J., Wang, Q., Chen, X., Sandberg, M., Zhu, W., Buccolieri, R., et al. (2015). City breathability in medium density urban-like geometries evaluated through the pollutant transport rate and the net escape velocity. Building and Environment, 94(P1), 166-182.

Ignatius, M., Wong, N.H. and Jusuf, S.K. (2015). Urban microclimate analysis with consideration of local ambient temperature, external heat gain, urban ventilation, and outdoor thermal comfort in the tropics. Sustainable Cities and Society, 19, 121-135.

Jae-Jin, K. and Jong-Jin, B. (1999). A numerical study of thermal effects on flow and pollutant dispersion in urban street canyons. Journal of Applied Meteorology, 38(1988), 1249.

Louka, P., Vachon, G., Sini, J.-F., Mestayer, P.G. and Rosant, J.-M. (2002). Thermal effects on the airflow in a street canyon-Nantes'99 experimental results and model simulations. Water, Air, and Soil Pollution, 2, 351-364.

MOHURD. (2016). Code for Thermal Design of Civil Building (GB 50176 - 2016). China Architecture \& Building Press, Beijing (China).

Nazarian, N. and Kleissl, J. (2016). Realistic solar heating in urban areas: Air exchange and street-canyon ventilation. Building and Environment, 95, 75-93.

O'Malley, C., Piroozfar, P., Farr, E.R.P. and Pomponi, F. (2015). Urban Heat Island (UHI) mitigating strategies: A case-based comparative analysis. Sustainable Cities and Society, 19, 222-235.

Panagiotou, I., Neophytou, M.K.A., Hamlyn, D. and Britter, R.E. (2013). City breathability as quantified by the exchange velocity and its spatial variation in real inhomogeneous urban geometries: An example from central London urban area. Science of the Total Environment, 442, 466-477.

Ramponi, R., Blocken, B., de Coo, L.B. and Janssen, W.D. (2015). CFD simulation of outdoor ventilation of generic urban configurations with different urban densities and equal and unequal street widths. Building and Environment, 92, 152-166.

Richards, P.J. and Hoxey, R.. (1993). Appropriate boundary conditions for computational wind engineering models using the $\mathrm{k}-\epsilon$ turbulence model. Journal of Wind Engineering and Industrial Aerodynamics, 46-47, 145-153.

Saneinejad, S., Moonen, P. and Carmeliet, J. (2014). Coupled CFD, radiation and porous media model for evaluating the micro-climate in an urban environment. Journal of Wind Engineering and Industrial Aerodynamics, 128, 1-11.
Santiago, J.L., Krayenhoff, E.S. and Martilli, A. (2014). Flow simulations for simplified urban configurations with microscale distributions of surface thermal forcing. Urban Climate, 9, 115-133.

Shahrestani, M., Yao, R., Luo, Z., Turkbeyler, E. and Davies, H. (2015). A field study of urban microclimates in London. Renewable Energy, 73, 39.

Taleghani, M., Kleerekoper, L., Tenpierik, M. and Van Den Dobbelsteen, A. (2015). Outdoor thermal comfort within five different urban forms in the Netherlands. Building and Environment, 83, 65-78.

The Population Division. (2018). World Urbanization Prospects 2018: Key Facts. New York.

Tong, Z., Chen, Y., Malkawi, A., Liu, Z. and Freeman, R.B. (2016). Energy saving potential of natural ventilation in China: The impact of ambient air pollution. Applied Energy, 179, 660-668.

Toparlar, Y., Blocken, B., Vos, P., Van Heijst, G.J.F., Janssen, W.D., van Hooff, T., et al. (2015). CFD simulation and validation of urban microclimate: A case study for Bergpolder Zuid, Rotterdam. Building and Environment, 83, 79-90.

Uehara, K., Murakami, S., Oikawa, S. and Wakamatsu, S. (2000). Wind tunnel experiments on how thermal stratification affects flow in and above urban street canyons. Atmospheric Environment, 34(10), 15531562.

WU, S. (2005). Aridity/humidity status of land surface in China during the last three decades. Science in China Series D, 48(9), 1510.

Yuan, C. and Ng, E. (2012). Building porosity for better urban ventilation in high-density cities - A computational parametric study. Building and Environment, 50, 176-189. 